UDC: (811.111:378.124):355.55 https://doi.org/10.22190/JTESAP2003231S

\title{
RECONSIDERING TEACHERS' VIEWS ON THE PROCESSES OF COURSE DESIGN AND TEACHING MATERIALS SELECTION IN THE CONTEXT OF ENGLISH FOR ACADEMIC PURPOSES
}

\author{
Elena Spirovska \\ South East European University, \\ E-Mail e.spirovska@seeu.edu.mk
}

\begin{abstract}
The aim of this article is to analyze, from teachers' point of view, the processes of needs analysis, syllabus design and the materials selection and adaptation in the context of English for Academic Purposes (EAP). These aspects of course design will be presented by examining in more detail the existing teachers' views and opinions on the factors which influence syllabus design, materials selection and deciding on the grading criteria. English for Academic Purposes is a discipline which emerged and was developed from English for Specific Purposes (ESP) context. The context of English for Academic Purposes is defined by a number of authors as a discipline which focuses on language learning in academic contexts and improving skills which can be transferred beyond the language curriculum and used in every area of academic studies. Some examples of these skills include the following: writing, research, presentation skills, providing arguments and debating. The research for the study is conducted by review of the relevant literature and previous studies on the topic, in addition to examining teachers' attitudes via open-ended interview questions.
\end{abstract}

Key words: English for Academic Purposes, teachers' views, course design, materials

\section{INTRODUCTION}

The aim of this paper is to provide theoretical as well as empirical research on the process of establishing course aims and objectives, materials selection and setting assessment criteria in the context of teaching English for Academic Purposes courses, designed and provided by the Language Centre at South Eastern European University in Tetovo, Republic of North Macedonia.

\section{ENGLish For ACADEMIC PURPoSES - DEFining THE PURPoSEs, CONTENT AND} SETTING, DifFERENTIATING BETWEEN GENERAL ENGLISH COURSES AND EAP

The theoretical framework for English for Academic Purposes courses offers several definitions. Jordan (1997, p.1) mentions the first official use of the term English for Academic Purposes. According to him, the term was used and recorded initially in 1974. By 1975, the term was in widespread use. The definition (ETIC, 1975) in Jordan (1997p.1) of English for 
Academic Purposes states the following: "EAP is concerned with those communication skills in English which are required for study purposes in formal education systems". This definition specifies the essential aim of English for Academic Purposes courses, which is to provide tertiary education students with skills which can facilitate their learning and their study progress in an academic teaching and learning environment and enable them to use those skills in both foreign language (native language classroom) as well as content areas. This notion is also supported by Dudley-Evans and St. John (199:34), who state the following about EAP courses: "English for Academic Purposes (EAP) refers to any English teaching that relates to study purposes. Students whose first language is not English may need help with both the academic discipline and the specific study skills required of them during their academic course."

According to Gillett (2011) the content of EAP courses, apart from language instruction, includes the following skills:

- Research and using the library;

- Using sources and referring to sources correctly;

- Paraphrasing, summarizing, describing processes and developments, providing arguments and reasons, describing a sequence of events, developing arguments and ideas, refuting arguments and drawing conclusions;

- Writing skills: organization, presentation, including graphs and charts, revising and proofreading.

Zohrabi (2010) argues that the EAP emphasis is on the common core rather than specific subject matter which would encompass the language system (vocabulary, grammar), study skills, language skills and communicative elements. The essence of EAP courses according to him is preparing students to tackle their university courses and to be able to function properly in their area of studies.

Alexander $(2008$, p.3) explains the differences between general ELT and teaching English for Academic Purposes. The division, which can be applied to the context of EAP, can be summarised in the following terms and as follows:

1. Syllabus: the focus of general ELT syllabus is on the aims and goals presently (what the student can or cannot do presently, while EAP syllabus is focused on future goals in terms of academic skills.

2. Teacher-student roles: Alexander (2008) differentiates between the unequal roles of students and teachers in general ELT situations (teachers are seen as experts and more dominant in comparison to students) and equal (in terms of EAP courses, where both are learning about the academic environment).

3. Language content in general ELT situations is unlimited and students need to be equipped for a wide range of communicative situations. In EAP the content is limited to academic discourse and associated grammar and discourse features.

4. Language skills balance: while speaking and listening are predominantly addressed in the context of general English, the emphasis in EAP is on reading and writing.

5. Study skills: while in general ELT situations, there is very little emphasis on study skills, EAP focuses on developing learning skills, particularly learner autonomy, cognitive skills and critical thinking. Gillett (2011) argues that it is useful to make a distinction between general study skills that are not related to language instruction and language study skills, which will form an essential component of EAP courses, for instance planning essays and acquiring formal language. 
After the first step of defining the course aims and objectives of English for Academic Purposes courses, the next step is structuring the course syllabus and weekly schedule. In the context of English for Academic Purposes courses, the aspects of the course design and the emphasis put on them are subjects of an ongoing debate. Jordan (1997) lists the factors which need to be taken into consideration when creating a syllabus for EAP courses. This list includes the following: needs, aims, means (the teachers, materials, facilities, time, and financial factors) and the variables/constraints (lack of teachers, time, financial means or materials). All of these factors are to be taken into consideration when planning English for Academic Purposes course syllabi.

Needs analysis or needs assessment was predominantly conducted via informal discussions with students in terms of their expectations of the course and their perceived needs based on content area courses and needs for academic skills. For instance, academic writing and delivering a formal presentation are transferable skills which are incorporated in other courses offered by the faculties. It is reasonable to infer that the students will benefit from the instruction and practice.

The number of hours for both Academic and Advanced Academic English equals to four 50 minutes classes per week or 60 hours per semester. Usually, they are scheduled as block of 2 hours with 10 minute break in-between, twice per week.

\section{ENGLish For ACADEMIC PuRposes COURSES TARgEt Population}

English for Academic Purposes (EAP) courses are introduced in the language learning curriculum and taught for the past nine years at South East European University Republic of North Macedonia. When enrolling at SEEU, new students are tested for their English proficiency level. The proficiency test is created for the needs of the institution and so far, it proved to be quite reliable and precise. The majority of the students are placed in one of the four General English levels: elementary (level 1) pre-intermediate (level 2) and intermediate (level 3 and 4).

The students whose language proficiency level is upper-intermediate are placed in Academic English groups. During some periods in the past, due to lack of teachers, monetary cuts or other factors, including the requirements of the faculties, these students were exempt from taking English language courses during their first year of studies and awarded automatically the credits for the course. The first contact with English in a university setting for those students used to be ESP courses during their second year of studies. However, the need to introduce a language course at the beginning of their academic studies was soon perceived, which resulted in introducing Academic and Advanced Academic English courses. The course introduced in the first semester is Academic English, while Advanced Academic English is introduced in the second semester. Both are intended only for first year students from the following faculties: Faculty of Contemporary Social Sciences, Faculty of Contemporary Sciences and Technologies, Faculty of Law, Faculty of Business and Economics and Faculty of Languages, Cultures and Communication.

The number of students per each group varies from 15 to 25 , although, due to the course nature and content, it is very difficult to work with groups which exceed that number of students. The number of Academic English groups varies each academic year. Sometimes, according to the proficiency test, there are enough students to create 5-6 
groups. Sometimes, there are only two groups and approximately 30-40 students who are placed in this level. They are 18-20 years old, both male and female students and coming from diverse educational background and with differences in their language proficiency. Despite the fact that the placement test is introduced at the beginning of every academic year, the EAP groups may be described as mixed abilities groups.

\section{TEACHING MATERIALS IN THE CONTEXT OF EAP COURSES}

Robinson (1991) in Jordan (1997, p.127) states the following regarding textbooks: "No textbook is likely to be perfect, of course, and practical considerations, such as cost, may have to take precedence over pedagogic merit". Sheldon (1988, in Jordan, 1991 p.127) argues the following: "It is clear that course book assessment is fundamentally a subjective, rule of thumb activity, and that no neat formula, grid or system will ever provide s definitive yardstick". The quotes above illustrate some of the issues that EAP teachers have encountered in the context of teaching EAP.

The dilemma of selecting either a textbook or other teaching materials in the context of EAP courses offered by the Language Center was always present. Initially, no specific textbooks for EAP courses were selected. Instead, the choice of the course materials was based on the projected learning outcomes and the tasks and activities to be done in class. For instance, if the projected learning outcome was to introduce the students to the appropriate structure of thesis statements, the practice was to select several handouts from academic writing books, online sources and to adapt them according to the learning outcomes, needs of the students and other factors (whether handouts are interesting, understandable and if they offer possibilities for further practice). After several semesters, a textbook created for EAP was selected and introduced to the students. However, the reactions from the students and teachers using a textbook varied. Due to the fact that Academic English groups were mixed abilities groups, the reading texts presented in the textbook were not very understandable or accessible for some of the students. The majority of the students, as well as the teachers, during staff meetings or exam preparation weeks, stated the impression that the reading texts were too challenging at times, that the textbook did not include relevant or appealing topics and that the overall impression is that using a textbook only does not meet the criteria expected from EAP teaching materials. The questionnaire used in this study research addresses this issue.

\section{ASSESSMENT IN THE CONTEXT OF EAP COURSES}

The selection of assessment methods and design of assessment criteria was also debated in the context of EAP courses provided by the Language Center. Throughout a decade during which these courses were offered, different assessment methods were introduced. Occasionally, the course assessment would emphasize tests and final exams, placing the focus and the highest weight of the final grade on the final exam. This practice was not very successful, mainly due to the fact that placing the importance on the final exam cannot reflect the course aims and objectives of EAP courses. Another mode of assessment in these courses emphasized the written tasks, including research projects writing, essay writing, book reviews and film reviews, as well as other written tasks. This mode was also not very successful, due to the fact that it inevitably placed extreme 
importance or writing skills and written projects and less importance on other skills, which was not adequate to the perceived needs of the students. In any academic environment, students need other skills besides writing, including speaking, learning skills and other examples of academic skills. When it comes to assessment and forming assessment criteria, the most important premise was that it should reflect the learning goals and objectives. In addition, it was important not to overemphasize or neglect certain study and language skills and to achieve the necessary balance.

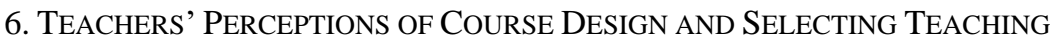 MATERIALS IN ENGLISH FOR ACADEMIC PURPOSES STUDY CONTEXT}

The purpose of this paper is to analyze teachers' views on the important issues related to English for Academic Purposes course design, the selection of teaching materials and forming the assessment criteria. The teachers, or EAP practitioners, responded anonymously in a written form to a questionnaire consisting 10 questions and additional notes related to their views on EAP issues. In total, 10 (ten) teachers responded to the questionnaire. The teachers are between 35-55 years of age and their teaching experience varies from 15-28 years. All of them taught English for Academic Purposes for at least one or more semesters. Therefore, their replies reflect their opinions related to EAP courses and need to be taken into consideration. The most illustrative responses to the questions will be presented below.

1. Which course aims and objectives should be prioritized, in your opinion, when creating a syllabus for Academic English courses?

- Developing transferable skills which will help them in meeting their short term needs related to their studies as well as their long term needs related to their future employability.

- It would depend on the setting/type of academic institution and whether students will be oriented more towards working or academic career. However, greater focus and real academic skills, like extensive reading, academic writing and research and less on skills development (communication, presentations, etc.).

- Developing critical thinking skills: critical reading, understanding and applying academic writing.

- I think that this depends on the institution itself and the policies, vision and mission they have. This pretty much sets the baseline upon which all courses are designed. But in the case of Language Center community, digital literacy and critical thinking skills should be prioritized. 
2. When creating a syllabus for Academic English courses, should the emphasis be given to skills which can be transferred/used in every academic setting (presentation skills, writing skills, debating)? Why/ Why not?

- Yes, definitely. Academic English courses should be focused on developing and improving students' writing and speaking skills.

- Yes, students should be able to use various communication strategies to participate in the discussions, to select and evaluate different resources and to form and support their opinion with arguments.

- Students should have developed their language skills and soft skills by this stage. The emphasis should be given to developing reading, writing and research.

- The emphasis should be given to transferable skills to meet students' needs related to content area courses, for instance presentations, note taking, paraphrasing or referencing.

3. When creating a syllabus for Academic English courses, should the emphasis be given to grammar, vocabulary and other traditional aspects of language learning? Why/ why not?

- Yes, but only as an integral part of writing, not as a focus on language by itself.

- No, it is important for students to produce accurate grammar forms and appropriate vocabulary but in the context of previously mentioned transferable skills.

- I think that there is space to incorporate that too, because they should not be mutually exclusive. They should be complementary.

4. Are materials and the process of materials selection important when creating a syllabus for Academic English courses? Why/ why not?

- I would say crucial, because achieving academic goals is based on books and the materials used.

- Very important. The more authentic the material, the more students will be exposed to real life situations and relate to the content.

- The materials and their selection are very important. However, the selection of materials should be done after the syllabus is created.

- Yes, the materials are very important, as they give directions in which way the course will be developed and oriented.

- Yes, they should be closely connected to the learning objectives.

- Yes, definitely. Materials should be selected from a variety of resources. I do not think that only one source (a book) is enough for teaching an EAP course. 
5. Is choosing an appropriate textbook for Academic English course design important? Why? Why not?

- Yes and no. A textbook comes with an already designed course syllabus and provides students with security, in the sense that they will know what to expect. However, textbooks sometimes include boring texts and activities and the material is not authentic.

- I do not believe that one course book can satisfy the needs of EAP courses, because of the variety of course goals and objectives.

- Yes, because it might have a serious impact on the ways you deliver the course and the quality of teaching.

- The textbook chosen must include materials that would meet the identified students' needs and the specified goals and objectives listed in the syllabus. Choosing a textbook should be the last stage of the course design.

- Yes, but it is not necessary. The teacher should be able to teach this course using a variety of resources.

6. When selecting a textbook for Academic English, which selection criteria should be taken into consideration?

- I do not think that only one textbook is enough for teaching an EAP course. The textbook should be used together with other additional materials.

- Topics, content and vocabulary.

- Availability, the price of the textbook. The teaching methodology it is based upon. Appropriateness of the topics. Additional materials available online and online support for students' autonomous work outside a class.

- User-friendly, understandable, easy to navigate and visually appealing.

7. Are authentic materials (visual/audio/texts) useful in the context of Academic English? If yes, what are the benefits? If no, what are the reasons?

- Authentic materials are very important as they expose the students to the real language and should enable students to communicate on their own, without teacher's guidance.

- Yes, students love authentic materials. They are more appealing and more useful.

- Authentic materials are very useful. Students get to listen or watch authentic conversations and native speakers. They develop both listening and speaking skills.

- They are very useful. Authentic materials bring the outside world in the classroom and build academic vocabulary. 
8. What are the most notable issues/problems when selecting teaching materials for Academic English courses?

- Not appropriate in terms of difficulty and not tailored to students' needs.

- Text adaptation, authenticity, relevance of the material for the students.

- Students' needs and topics of their interest.

- Most of the materials are too specific. For instance, they prepare the students for taking a certain test. In addition, textbooks for EAP courses are focused on reading and writing, whereas speaking is slightly neglected.

9. When setting assessment and grading criteria for Academic English courses, do you believe that the priority should be given to tests, final exams and quizzes. Should the priority be given to presentations, debates and written assignments? Why? Why not?

- It all depends on the goals that should be achieved.

- Exams and tests should not be used. Other forms of more authentic assessment should be used.

- Presentations, debates and written assignments engage students and provide practice for students. They develop their argumentative skills.

- Tests of any kind only measure what students memorized. Other assessment tasks show how students apply their knowledge.

- No tests. Creativity and higher order thinking skills should be the focus of EAP courses and they are not measured by tests.

10. Your comments and thoughts on the issue of Academic English course design, materials selection and assessment criteria.

- EAP courses should prepare students for continuation of their academic study and future career. Therefore they should be developed and organized in this regard. If this means that only certain students attend them, as a kind of ESP it should not be an issue. Another option for developing EAP courses is preparation for standardized tests and preparing the students for academic environments in English speaking countries. So, the emphasis should be on acquiring academic skills.

- Every EAP course should balance satisfying students' immediate study-related needs and long terms employability skills. The course design should start by analyzing students' needs, specifying the course aims and objectives, the most appropriate teaching methodology and finally selecting the most appropriate teaching materials, adapting and supplementing them. The assessment criteria must ensure continuous assessment which allows students to use the language learned and not just memorize rules and reproduce them. 


\section{DiSCUSSION, CONCLUSIONS AND RECOMMENDATIONS DRAWN FROM TEACHERS' OPINIONS}

The comments and responses on the questionnaire presented above provide important insight into the aspects of syllabus creation, materials selection and assessment in the context of EAP courses. The responses reflect the need of developing critical reading and critical thinking skills, digital literacy and research skills as well as academic writing. According to teachers' responses, the emphasis should be given to reading and writing skills, as well as skills which are transferable and can be used in any academic setting and content area courses. Grammar and vocabulary should be incorporated in the context of teaching other content. However, they should not be taught independently.

Teachers' responses clearly state that the materials in the context of EAP courses are crucial and the process of their selection is very important and that they should address the learning goals and objectives. According to the responses, materials should be chosen from a variety of resources. According to the participants' responses, a textbook is important but not necessary. Furthermore, they believe that using one textbook only cannot meet the needs of EAP course. According to them, selecting a textbook should be a step which follows after defining the course goals and objectives. Among the relevant factors when selecting a textbook for EAP courses are appropriateness, availability, the price of a specific textbook. In addition, visual attractiveness, relevance of topics and online support are also noted. Participants state that assessment should not rely on exams and quizzes. Instead, assessment should rely on a number of tasks which ensure continuous assessment such as research projects, presentations, debates and a variety of written tasks.

Participants also emphasize the need of addressing students' academic skills and preparation for further academic study. In this regard, one of the suggestions is that EAP courses should include an element of preparation for standardized tests of English, for instance TOEFL, IELTS, or other similar tests, which are required for scholarship opportunities and study programs.

Several conclusions can be derived from the analysis of the theoretical overview and reviewing participants' response and the teaching practices so far, the following conclusions can be reached. First, it can be concluded that English for Academic Purposes courses are considered necessary and indeed a very important part of tertiary education. The function of EAP courses should not be limited to completing the necessary number of credits or filling in a gap between the secondary and tertiary language education. EAP courses should focus their aims and objectives on critical reading and thinking, facilitating students' academic skills and introducing the concept of study skills to students who are already proficient, for instance research skills, project and essay writing, listening, presenting, stating arguments and participating in a debate. It is important to understand that these study skills extend beyond language education and are needed for the majority of academic courses, including content area courses. The students, especially in the educational context in which their content area courses are delivered in English, should be aware of the necessity of the study skills and the fact that they are transferable and used in every academic setting.

The second important conclusion is that the course goals and objectives should be reflected in grading criteria and assessment, which should be balanced in terms of assessed tasks, without overemphasizing tests, exams or quizzes. Instead, importance should be placed on research projects, written projects and projects which allow assessment of students speaking skills. 
The third important conclusion pertains to the course materials. The selection of the course materials should follow the process of analyzing students' needs and defining course goals and objectives. The course materials cannot be limited to a single course book only, regardless of the quality and relevance of it. If a textbook is chosen, it needs to relevant and accessible, supported by online additional resources or other handouts and additional materials. Therefore it can be concluded that the best choice of materials in the context of EAP course would be a blend of materials, based on an appropriate textbook and upgraded with supplementary materials/handouts. These conclusions and recommendations were derived from the theoretical overview of the relevant literature, but even more from the experience and practices in the context of designing English for Academic Purposes courses at the South East European University.

\section{REFERENCES}

Alexander, Owen., Argent, S. and J. Spencer 2008. EAP Essentials: A teacher's guide to principles and practice. Reading: Garnet Publishing Ltd.

Dudley-Evans T. and M.J. St John 1998. Developments in ESP: A multi-disciplinary approach. Cambridge: Cambridge University Press. ISBN 0521596750.

Gillett, A.J. (2011) What is EAP? Accessed from http://www.uefap.com/bgnd/

Jordan, Robert R. 1997. English for Academic Purposes: A guide and resource book for teachers. Cambridge: Cambridge University Press.

Zohrabi, M. "A New Outlook on EAP Literacies: General and Specific English Territories." Pan-Pacific Association of Applied Linguistics, Vol.14 No 2 (2010):165-186.

Retrieved from https://files.eric.ed.gov/fulltext/EJ920540.pdf 